\title{
ESTIMATION OF DAMAGE SEVERITY USING SPARSE STATIC MEASUREMENT
}

\author{
Ivana ŠTIMAC GRANDIĆ, Davor GRANDIĆ \\ Faculty of Civil Engineering, University of Rijeka, Radmile Matejčić 3, 51000 Rijeka, Croatia
}

Received 01 Apr 2014; accepted 06 Jan 2015

\begin{abstract}
A new structural damage estimation procedure using grey relation coefficient and curvature of displacement influence line in beams using sparse measurement is proposed in this paper. The method is based on static structural response which can be obtained using single sensor. Determination of damage location as well as determination of corresponding damage severity can be easily calculated with simple arithmetic operations, which is the main advantage of the proposed method. Conducted numerical simulation for different damage scenarios and various measurement sparseness and experimental validation confirm the effectiveness of proposed damage severity estimation procedure.
\end{abstract}

Keywords: damage estimation, static method, curvature, deflection influence line.

\section{Introduction}

Periodically monitoring of structures is essential to prevent the accumulation of damage which may result in structural failure. In the past few decades different nondestructive damage detection techniques (NDDT) are developed. NDDT can be categorised as global or local. The local techniques (X-ray, ultrasonic, etc.) can be effective if the damage location is known a priori, what cannot be expected in most civil engineering structures (Wang et al. 2011). Therefore, the global techniques are, firstly, developed to detect the presence of damage and estimate damage location (Cornwell et al. 1999; Li et al. 2002; Choi et al. 2004; Garstecki et al. 2004; Štimac Grandić et al. 2009; Abdo 2012). Secondly, many global NDDT are able to estimate severity of damage at damage location (Chen, Bicanic 2000; Nicholson, Alnefaie 2000; Kim et al. 2006; Štimac Grandić, Grandić 2010; Wang 2013; Fayyadha, Razaka 2013).

Since the static and dynamic responses of structure are functions of structural parameters, changes of these parameters will change a structural response. Thus, changes in static or dynamic structural responses can be used to determine the changes in structural parameters (such as mass, damping and stiffness).

The vibration-based NDDT are more fully developed in comparison to static-based ones. However, the static-based method have some advantages over the vibration-based: static tests are easily executable in comparison to dynamic ones and provide identification information without introduction uncertainties due to changes in mass and damping (Buda, Caddemi 2007), static-based NDDT are usually cheaper and more accurate than vibration-based NDDT, especially if ambient vibration are used (Abdo 2012), the vibration-based techniques inherently suffer from the incompleteness of measured modal data: only a few of the lower modes can be successfully measured, the complete sets of degrees of freedom cannot be measured and the complete spatial resolution of mode shape cannot be achieved (Kim et al. 2006). In regard to mentioned shortcomings some authors proposed techniques utilizing only static information (Sanayei et al. 1997; Maity, Saha 2004; Buda, Caddemi 2007; Lee, Eun 2008; Yang, Sun 2011; Abdo 2012; Seyedpoor, Yazdanpanah 2013; Viola, Bocchini 2013).

As well as in dynamic tests, incompleteness of static information due to limited number of sensors is a great problem in static tests. This problem can be overcome by using influence line approach where only one sensor is sufficient to obtain the influence line.

The usability of static NDDT using influence line approach in damage localization has been presented by several researchers (Choi et al. 2004; Stöhr et al. 2006; Štimac Grandić et al. 2011; Wang et al. 2011) but none of them try to evaluate severity of damage.

In this paper, a novel static NDDT based on a displacement influence line curvatures for identifying the location and seveof damage, focusing on sparse measurement, is proposed. Verification of proposed technique is done by numerical simulations and experimental test.

Corresponding author: Ivana Štimac Grandić

E-mail: istimac@gradri.uniri.hr 


\section{Theoretical formulation}

For a linear structure, by Maxwell's reciprocity theorem, the displacement at point $a$ due to a load acting at point $b$ equals the displacement at point $b$ due to load acting at point $a$ (Reddy 1996). It means that deflection line $w(x)$ of the structure loaded with force $F$ at the point $a$ equals the deflection influence line $\eta_{w}(x)$ obtained at the location $a$ for different position of force $F$. Reciprocity theorem facilitates obtaining the displacement along the entire structure using single sensor.

Consider a beam that can be treated as geometrically and materially linear in the intact and damaged states. In general, the curvature $\kappa(x)$ is defined as:

$$
\kappa(x)=\frac{\frac{d^{2} w(x)}{d x^{2}}}{\left[1+\left(\frac{w(x)}{d x}\right)^{2}\right]^{\frac{3}{2}}},
$$

where $w(x)$ is the deflection of the beam. If deflections are much smaller than the beam length Eqn (1) turns to:

$$
\kappa(x)=\frac{d^{2} w(x)}{d x^{2}}
$$

Using the fact that $w(x)=\eta_{w}(x)$ the curvature of deflection influence line is:

$$
\kappa(x)=\frac{d^{2} \eta_{w}(x)}{d x^{2}} .
$$

In bent beams, where influence of transversal force on curvature may be neglected, the relationship between curvature, bending moment $M(x)$ and bending stiffness $E I(x)$ can be written as:

$$
\kappa(x)=\frac{M(x)}{E I(x)} .
$$

For damaged beam Eqns (3) and (4) can be rewritten in form:

$$
\begin{gathered}
\kappa^{*}(x)=\frac{d^{2} \eta_{w}{ }^{*}(x)}{d x^{2}} ; \\
\kappa^{*}(x)=\frac{M^{*}(x)}{E I^{*}(x)} .
\end{gathered}
$$

In statically determinate beam bending moment is not dependent of the bending stiffness, $M(x)=M^{*}(x)$, then it can be concluded that changes in the curvatures between two stages of structure is caused by changes in the bending stiffness:

$$
\frac{E I^{*}(x)}{E I(x)}=\frac{\kappa(x)}{\kappa^{*}(x)} .
$$

Although the difference between the displacement influence lines for intact and damaged structures (Choi et al. 2004; Štimac Grandić et al. 2011) as well as difference of rotation of displacement influence lines can be used for damage localization (Štimac Grandić et al. 2011) the absolute difference in the curvature of displacement influence lines is the most sensitive influence line-based method (Wang et al. 2011).

In the non-damaged segments of the beam the difference of the curvatures equals zero. The value(s) of absolute difference in curvatures which is not equal to zero points to damaged beam's segment (Štimac et al. 2007; Štimac Grandić et al. 2011).

\section{Damage severity estimation algorithm}

When analytical representation of displacement influence line is not available, as it is in the case of experimentally measured or numerically obtained displacement influence line, the calculation of curvature has to be performed numerically.

Suppose the beam is divided in $n$ equal segments as it is presented in Figure 1. The displacements are obtained at the beginning and at the end of each segment $j$ (at $x_{i-1}$ and $x_{i}$ ), where $j=1$ to $n$ and $i=0$ to $n$.

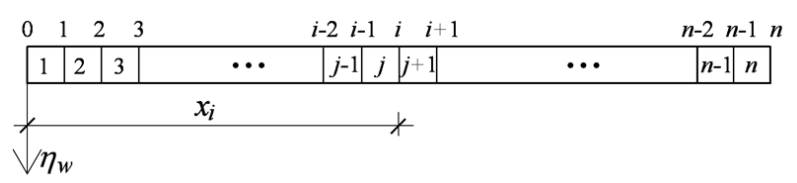

Fig. 1. A schema of a beam's segments

The curvature $\kappa\left(x_{i}\right)$ at the data site $x_{i}$ can be calculated using second central finite difference:

$$
\kappa\left(x_{i}\right) \approx \frac{\eta_{w}\left(x_{i-1}\right)-2 \cdot \eta_{w}\left(x_{i}\right)+\eta_{w}\left(x_{i+1}\right)}{\left(x_{i}-x_{i-1}\right) \cdot\left(x_{i+1}-x_{i}\right)},
$$

where $\eta_{w}\left(x_{i}\right)$ is the value of displacement influence line at the position $x_{i}, \eta_{w}\left(x_{i-1}\right)$ and $\eta_{w}\left(x_{i+1}\right)$ are the values of displacement influence line at the positions $x_{i-1}$ and $x_{i+1}$, respectively.

According to Eqn (8) the curvature for damaged state can be written as follows:

$$
\kappa^{*}\left(x_{i}\right) \approx \frac{\eta_{w}{ }^{*}\left(x_{i-1}\right)-2 \cdot \eta_{w}{ }^{*}\left(x_{i}\right)+\eta_{w}{ }^{*}\left(x_{i+1}\right)}{\left(x_{i}-x_{i-1}\right) \cdot\left(x_{i+1}-x_{i}\right)} .
$$

If damage is represented as reduction in bending stiffness $E I^{*}=(1-\delta) E I$, the decrease in bending stiffness $\delta_{j}$ inside the segment $j$, can be express as:

$$
\delta_{j}=1-\frac{\kappa_{j}}{\kappa^{*}{ }_{j}},
$$

where $\kappa_{j}$ and $\kappa_{j}^{*}$ are intact and damaged curvature of the segment $j$. In non-damaged segment(s) $\delta_{j}=0$ while in damaged ones $0<\delta_{j}<1$.

The curvatures $\kappa\left(x_{i}\right)$ and $\kappa^{*}\left(x_{i}\right)$, at the position $x_{i}$ $(i=1$ to $n-1)$ calculated according to Eqns (8) and (9) 
can be treated as average curvature at the adjacent segments $j$ and $j+1$ :

$$
\begin{gathered}
\kappa\left(x_{i}\right)=\bar{\kappa}_{j_{\left(x_{i}\right)}}=\bar{\kappa}_{j+1_{\left(x_{i}\right)}} ; \\
\kappa^{*}\left(x_{i}\right)=\bar{\kappa}_{j_{\left(x_{i}\right)}^{*}}^{*}=\bar{\kappa}_{j+1_{\left(x_{i}\right)}}^{*} .
\end{gathered}
$$

Then:

$$
\delta\left(x_{i}\right)=1-\frac{\kappa\left(x_{i}\right)}{\kappa^{*}\left(x_{i}\right)}=\bar{\delta}_{j_{\left(x_{i}\right)}}=\bar{\delta}_{j+1_{\left(x_{i}\right)}} .
$$

Suppose the damage is placed within a single segment $j$. The curvatures in position $x_{i-1}$ and $x_{i}$ for damaged state will be different from curvatures for intact state at the same positions, therefore $\delta\left(x_{i-1}\right) \neq 0$ and $\delta\left(x_{i}\right) \neq 0$. According the Eqn (13) calculated vales $\delta\left(x_{i-1}\right)$ and $\delta\left(x_{i}\right)$ shows the average value of decrease in bending stiffness in segments $j-1$ to $j$ and $j$ to $j+1$, respectively. As we know that there is no damages in segments $j-1$ and $j+1$ it can be concluded that decrease in bending stiffness $\delta_{j}$, in segment $j$, is average of twice the values $\delta\left(x_{i-1}\right)$ and $\delta\left(x_{i}\right)$. It should be noted that curvatures according to Eqns (8) and (9) could be calculated in positions $i=1$ to $n-1$.

Therefore the decrease in bending stiffness $\delta_{j}$ in segments $j=1$ and $j=n$ is twice the value $\delta\left(x_{1}\right)$ and $\delta\left(x_{n-1}\right)$, respectively.

Measurement errors, which may be attributed to environmental conditions, sensors or measurement accuracy cannot be avoided in field or laboratory test. Thus, theoretical assumption of zero curvature difference in nondamaged segments of the beam will not be fulfilled.

Hence, the grey relation coefficient $\zeta\left(x_{i}\right)$ is employed to detect the point of significant difference between curvature of damaged and non-damaged structure (Abdo 2012; Chen et al. 2005):

$$
\zeta\left(x_{i}\right)=\frac{\min R+0.5 \cdot \max R}{R\left(x_{i}\right)+0.5 \cdot \max R},
$$

where $R\left(x_{i}\right)=\left|\kappa\left(x_{i}\right)-\kappa^{*}\left(x_{i}\right)\right|$. The grey relation coefficient $\zeta\left(x_{i}\right)$ evaluates the degree of the correlation at the $i^{\text {th }}$ point of the curvatures of damaged and non-damaged structure. Generally, $\zeta\left(x_{i}\right) \geq 0.9$ indicates complete correlation; $0.8 \leq \zeta\left(x_{i}\right)<0.9$ indicates the good correlation of the two points; $0.6 \leq \zeta\left(x_{i}\right)<0.8$ indicates that the two points are relative possibly; $\zeta\left(x_{i}\right)<0.6$ represents that the two points are almost irrelative (Abdo 2012; Chen et al. 2005).

The value of $\zeta\left(x_{i}\right)=0.6$ will be accepted as a limit value for determination of damaged section. In the points where $\zeta\left(x_{i}\right) \geq 0.6$ it will be assumed that the difference in curvature is result of measuring errors, i.e. there is no changing in stiffness (damages) in the adjacent segments. The points where $\zeta\left(x_{i}\right)<0.6$ are considered as the points of changes in curvature which can be assigned to changes in stiffness.
The validity of this assumption can be seen in conducted researches (Chen et al. 2005; Abdo 2012) where for single or double damage scenarios the value of $\zeta\left(x_{i}\right)$ in damaged sections are below 0.6.

Based on the previous considerations the following damage severity estimation procedure based on simple arithmetic operations, shown in flow chart in Figure 2, is proposed.

Although the theoretical formulation is based on assumption of materially linear structure, the method can be successfully used for detection of changes in structural stiffness as result of changes in $E$-modules and/or moment if inertia $I$ as it is done in some previous researches (RaghuPrasad et al. 2013; Capozucca 2008; Ndambi et al. 2000, 2002).

\section{Numerical simulations}

The number and position of displacement data along the beam depend on different load positions. Theoretically, the spacing between two load positions can be very small, i.e. the displacement influence line can be constructed using the dense network of measurement data. The dense network of measured data is difficult to expect on field measurements.

In this chapter, the numerical simulations are used to test the usability of proposed damage severity algorithm in regard to different spacing between measured data (sparse measurement data).

The numerical analysis has been carried out for a simply supported beam with different positions and severity of damage. The span length of simply supported beam is $L=10 \mathrm{~m}$. The cross section area of a beam is $A=2190 \mathrm{~mm}^{2}$, the moment of inertia is $I=3830000 \mathrm{~mm}^{4}$ and Young's modulus is $E=200000 \mathrm{MPa}$. The applied force is $F=1 \mathrm{kN}$.

The displacement influence lines have been computed for point in the middle of the span for both the undamaged and the damaged state. The damage has been simulated by reducing the bending stiffness at the damaged section according to Table 1 .

In the first group of simulations the values of deflection influence lines are calculated at the distance of

Table 1. Damage scenarios on simply supported beam

\begin{tabular}{c|c|c}
\hline $\begin{array}{c}\text { Damage } \\
\text { scenario }\end{array}$ & $\begin{array}{c}\text { Position of damage(s) } \\
\text { from left support in } \\
\text { meters }\end{array}$ & $\begin{array}{c}\text { Reduction of } \\
\text { bending stiffness } \\
\text { in } \%\end{array}$ \\
\hline 1 & at $1.5-1.75$ & 10 \\
\hline 2 & at $1.5-1.75$ & 20 \\
\hline 3 & at $5.5-5.75$ & 10 \\
\hline 4 & at $5.5-5.75$ & 20 \\
\hline 5 & at $5.5-5.75$ & 30 \\
\hline 6 & at $0-0.25$ & 20 \\
\hline 7 & at $2.25-2.5$ & 30 \\
\hline
\end{tabular}




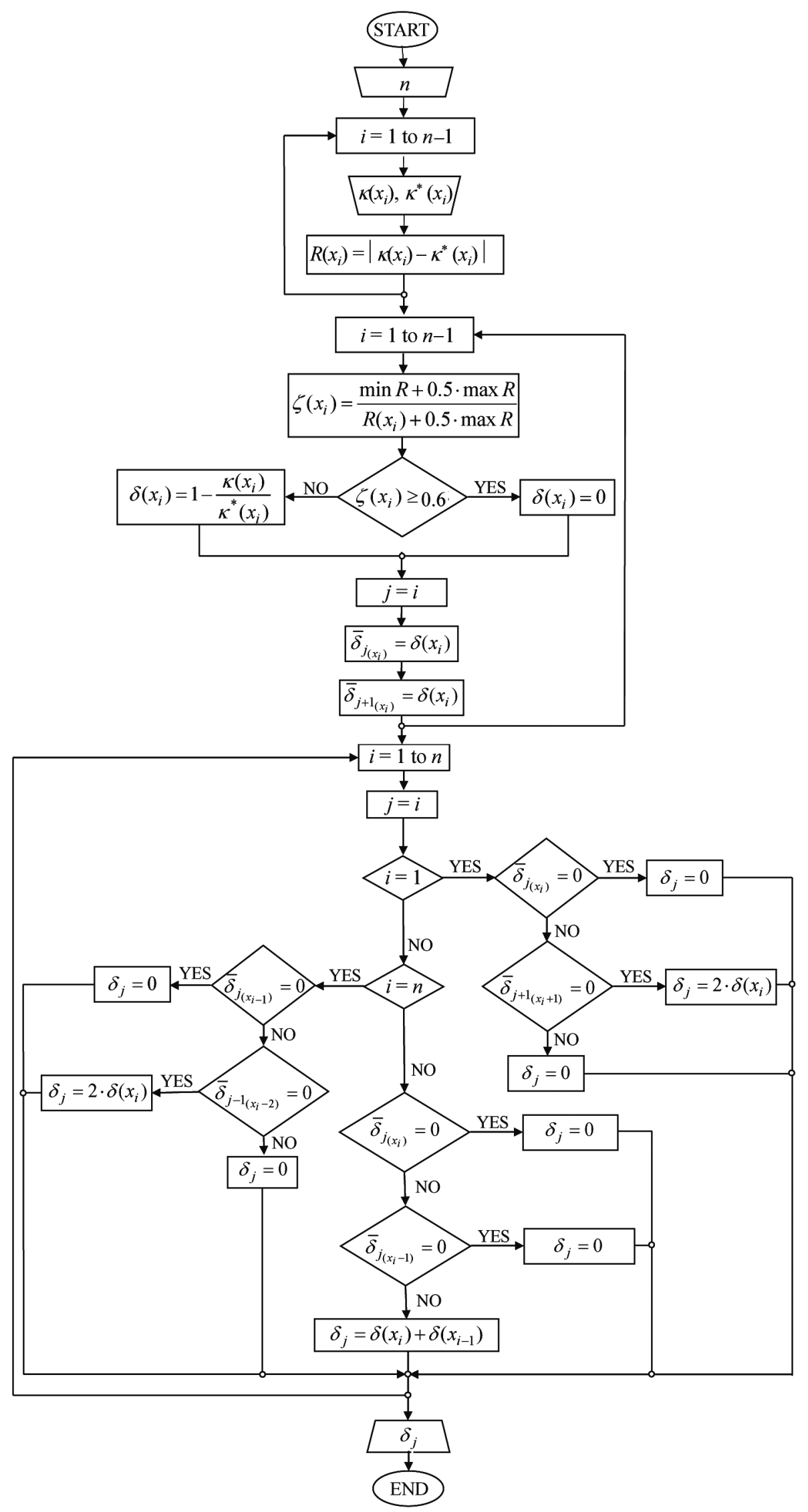

Fig. 2. A flow chart of proposed damage severity estimation procedure 
$d=0.25 \mathrm{~m}$ (the total number of segments is $n=40$ ). In the second group of simulations the distance of calculated values is $d=0.5 \mathrm{~m}(n=20)$, in the third group of simulations the distance $d=1 \mathrm{~m}(n=10)$.

The values of decrease in bending stiffness $\delta_{j}$ are calculated according to proposed damage severity estimation procedure shown in Figure 2.

In Figures 3 to 23 the calculated and simulated values of decrease in bending stiffness $\delta_{j}$ are shown for all conducted numerical simulations. In case of measurement sparseness $(d=0.5 \mathrm{~m}$ and $d=1.0 \mathrm{~m})$ the decrease of bending stiffness covers just a part of the segment. The damage can only be predicted with a resolution equal to the distance between the measured points, i.e. in whole segment, therefore the simulated values of decrease in bending stiffness $\delta_{j}$ in Figures 10-23 are expressed as the mean value of the decrease in bending stiffness in associated segment $j$.

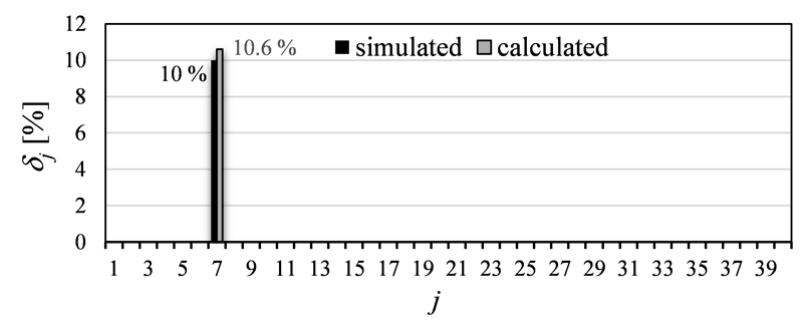

Fig. 3. $\delta_{j}$ in damage scenario $1(n=40, d=0.25 \mathrm{~m})$

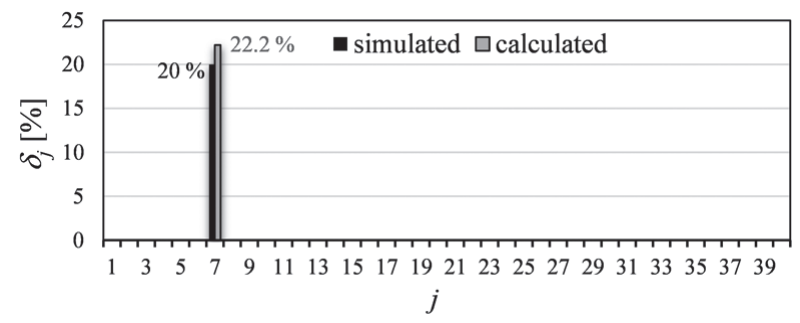

Fig. 4. $\delta_{j}$ in damage scenario $2(n=40, d=0.25 \mathrm{~m})$

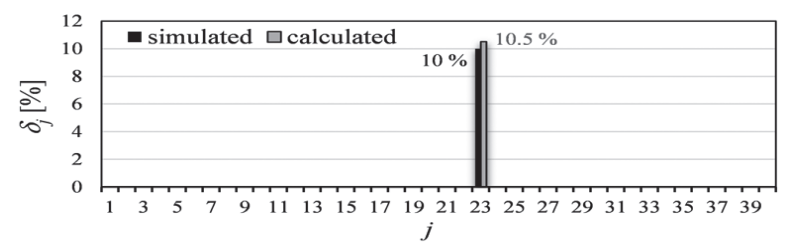

Fig. $5 . \delta_{j}$ in damage scenario $3(n=40, d=0.25 \mathrm{~m})$

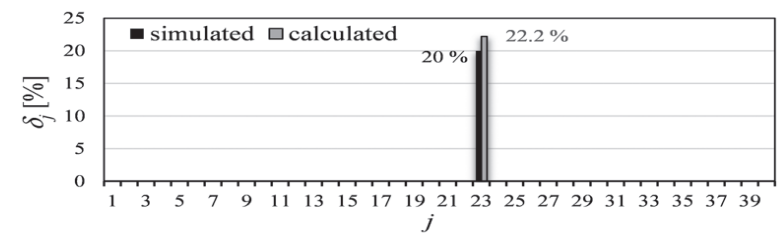

Fig. 6. $\delta_{j}$ in damage scenario $4(n=40, d=0.25 \mathrm{~m})$

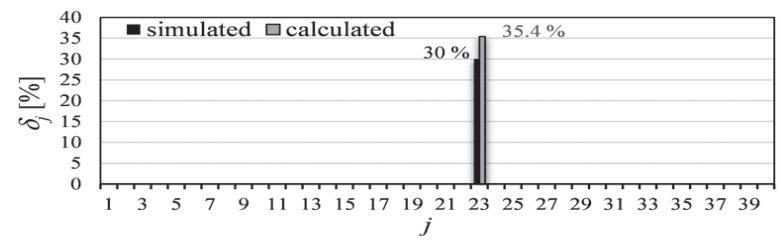

Fig. 7. $\delta_{j}$ in damage scenario $5(n=40, d=0.25 \mathrm{~m})$

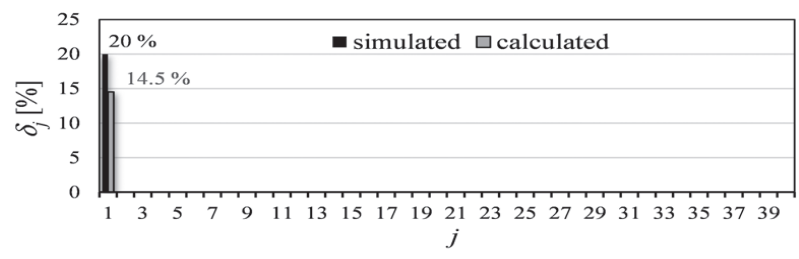

Fig. $8 . \delta_{j}$ in damage scenario $6(n=40, d=0.25 \mathrm{~m})$

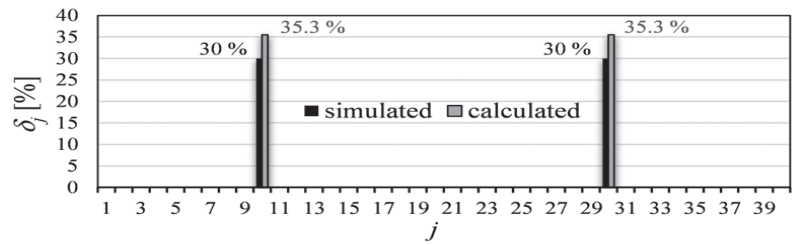

Fig. 9. $\delta_{j}$ in damage scenario $7(n=40, d=0.25 \mathrm{~m})$

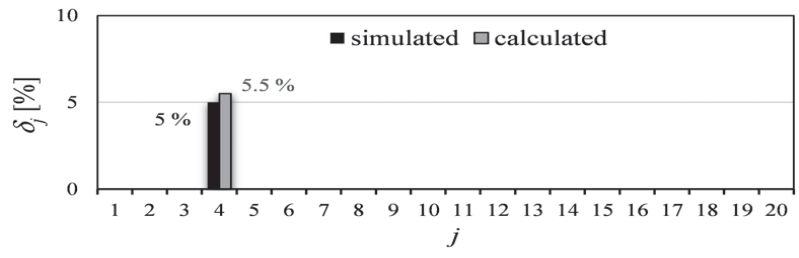

Fig. 10. $\delta_{j}$ in damage scenario $1(n=20, d=0.5 \mathrm{~m})$

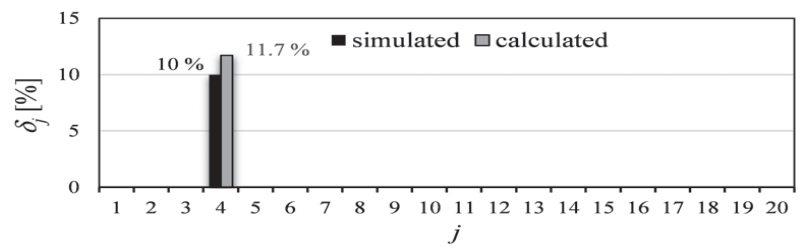

Fig. 11. $\delta_{j}$ in damage scenario $2(n=20, d=0.5 \mathrm{~m})$

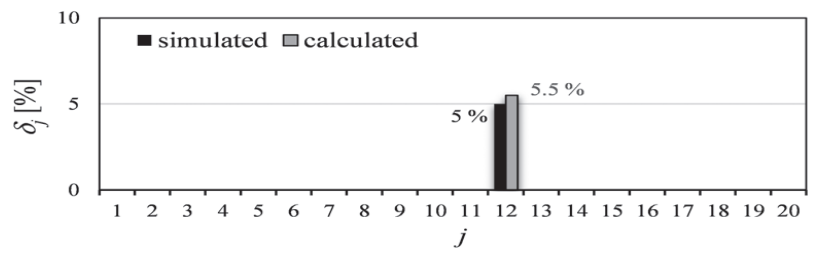

Fig. 12. $\delta_{j}$ in damage scenario $3(n=20, d=0.5 \mathrm{~m})$ 


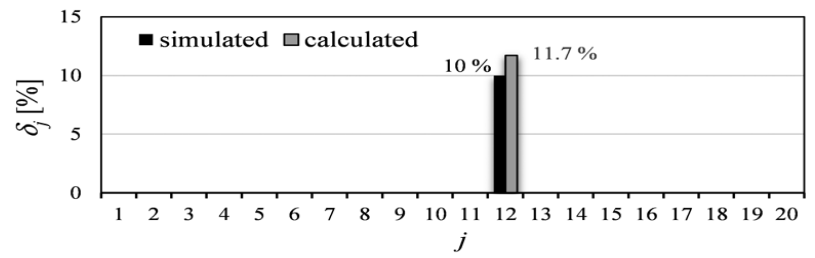

Fig. 13. $\delta_{j}$ in damage scenario $4(n=20, d=0.5 \mathrm{~m})$

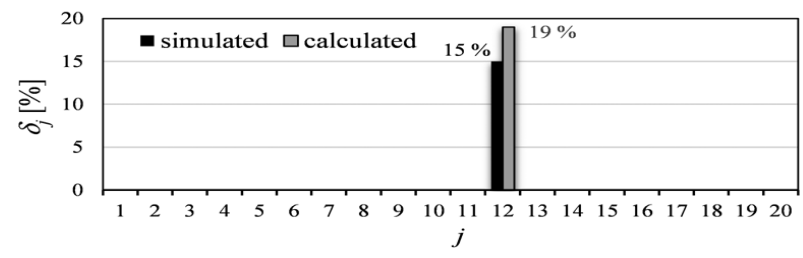

Fig. 14. $\delta_{j}$ in damage scenario $5(n=20, d=0.5 \mathrm{~m})$

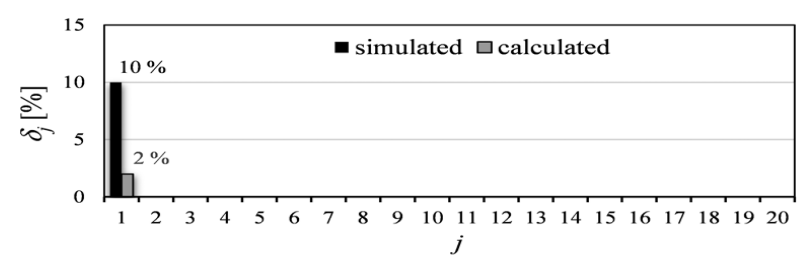

Fig. 15. $\delta_{j}$ in damage scenario $6(n=20, d=0.5 \mathrm{~m})$

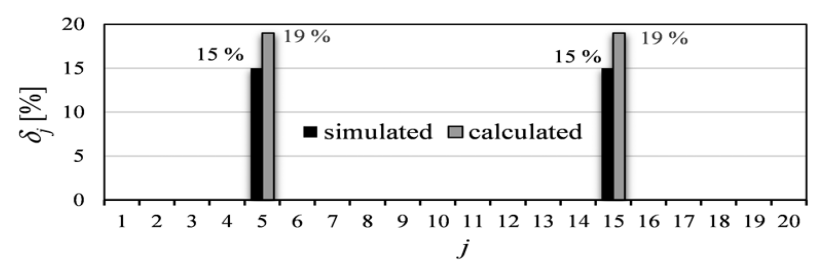

Fig. 16. $\delta_{j}$ in damage scenario $7(n=20, d=0.5 \mathrm{~m})$

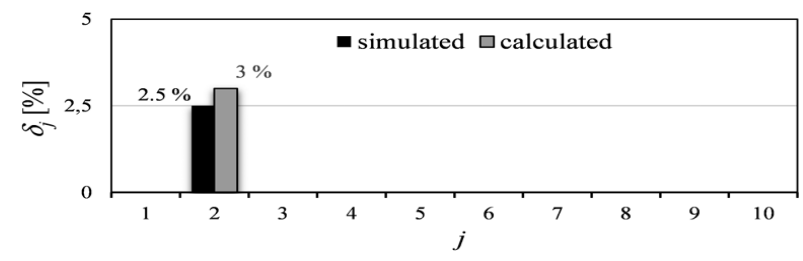

Fig. 17. $\delta_{j}$ in damage scenario $1(n=10, d=1 \mathrm{~m})$

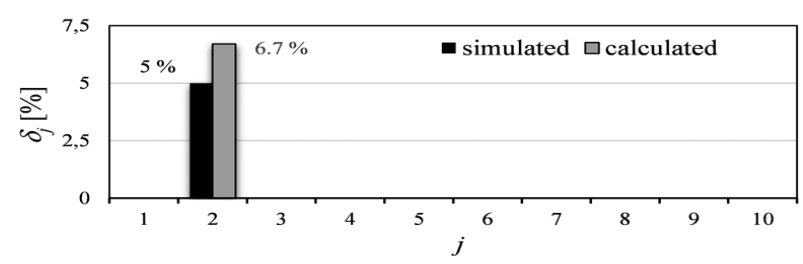

Fig. 18. $\delta_{j}$ in damage scenario $2(n=10, d=1 \mathrm{~m})$

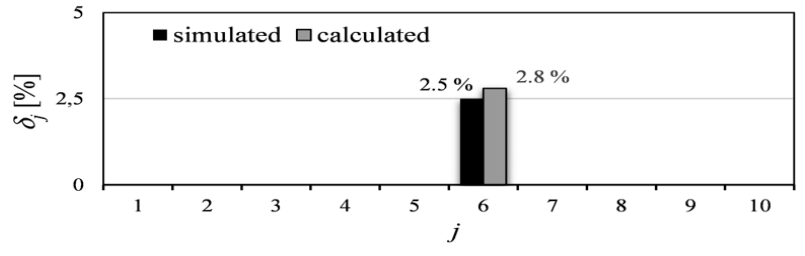

Fig. 19. $\delta_{j}$ in damage scenario $3(n=10, d=1 \mathrm{~m})$

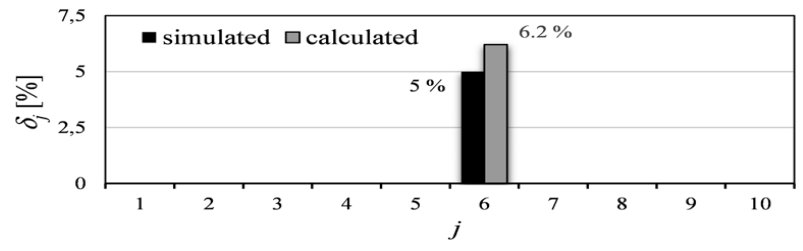

Fig. 20. $\delta_{j}$ in damage scenario $4(n=10, d=1 \mathrm{~m})$

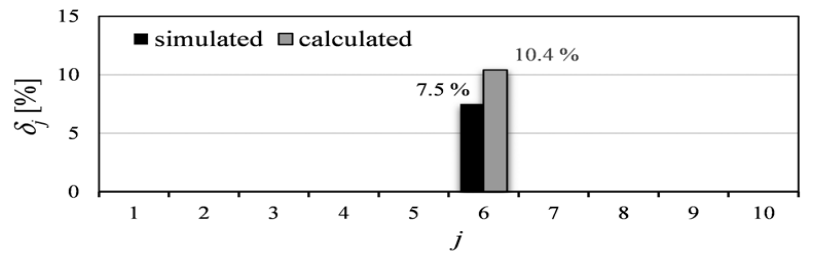

Fig. 21. $\delta_{j}$ in damage scenario $5(n=10, d=1 \mathrm{~m})$

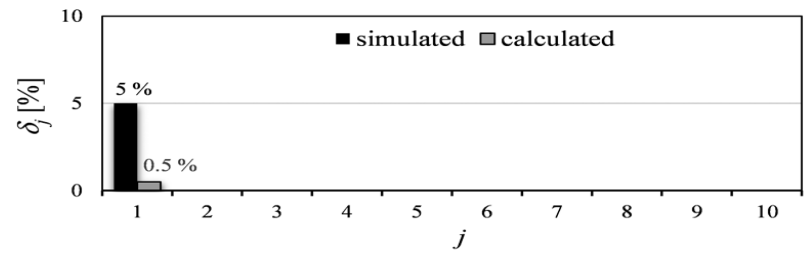

Fig. 22. $\delta_{j}$ in damage scenario $6(n=10, d=1 \mathrm{~m})$

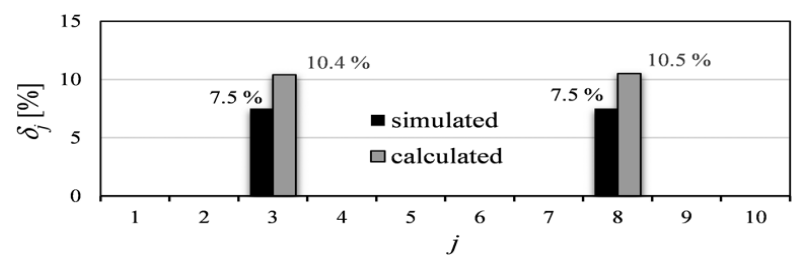

Fig. 23. $\delta_{j}$ in damage scenario $7(n=10, d=1 \mathrm{~m})$

\section{Experimental test}

Experimental validation of proposed method is done by using experimental obtained displacement influence lines. The experiment is carried out on the steel specimen shown in Figures 24 to 27 (Štimac 2006). The beam specimen had six longitudinal steel bars $(4 \phi 7 \mathrm{~mm}$ and $2 \phi 8 \mathrm{~mm})$ in the low part of specimen and two longitudinal bars $(2 \phi 7 \mathrm{~mm})$ at the top of the specimen. The longitudinal bars of the low and top part of specimen are connected together by mesh of bars of $\phi 4.2 \mathrm{~mm}$. The bars are welded to each other. 


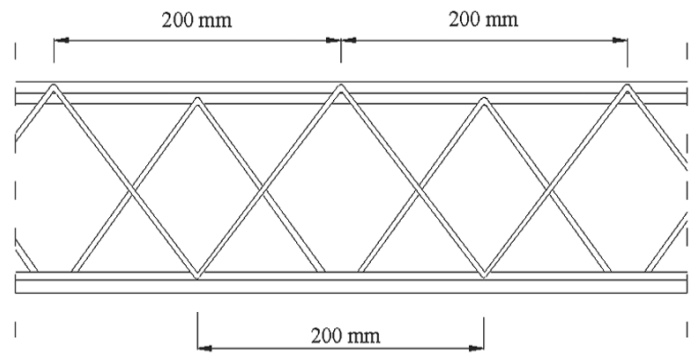

Fig. 24. The detail of the longitudinal view of the specimen

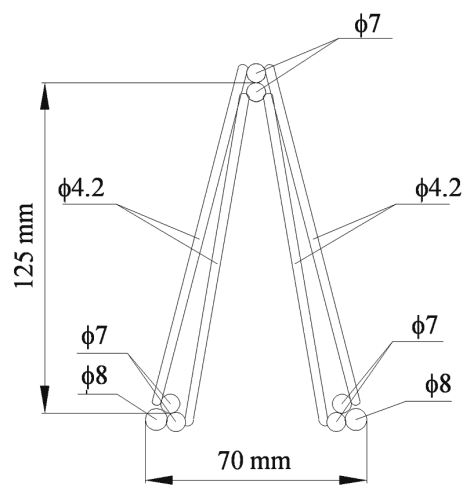

Fig. 25. The cross-section of the specimen

The moment of inertia of intact specimen is $I=1029252 \mathrm{~mm}^{4}$ and Young's modulus is $E=200000 \mathrm{MPa}$. The specimen was placed at pinned supports. The span length of the specimen is $L=6 \mathrm{~m}$.

In damaged specimen bars of $\phi 7 \mathrm{~mm}$, in the low part of specimen, were cut off at the position of 1.6 to 1.8 meters from the left support (Fig. 26).

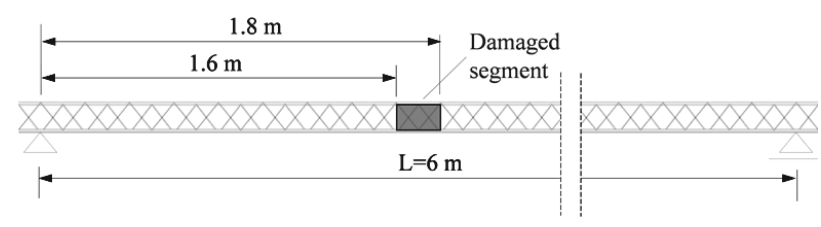

Fig. 26. The position of damaged segment

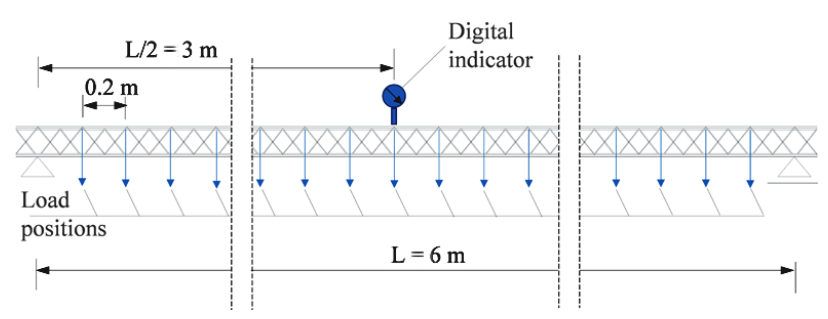

Fig. 27. The experimental set-up

The displacement influence lines for both (intact and damaged) specimens were constructed using measured middle-span displacements due to load applied successively every $20 \mathrm{~cm}$, starting from the left support, by hanging the weight of $0.13 \mathrm{kN}$ at each load position.
The displacements are obtained by digital indicator (resolution of $0.001 \mathrm{~mm}$ ). The experimental set-up can be seen in Figure 27.

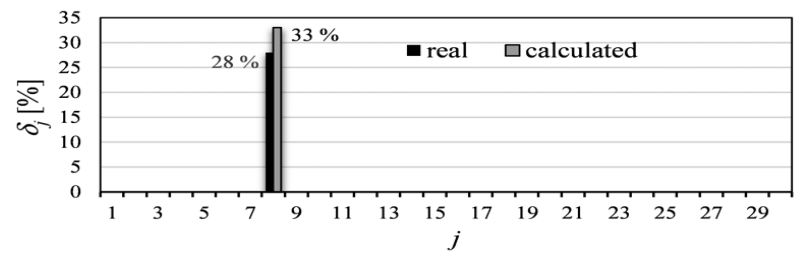

Fig. 28. The real and calculated values of $\delta_{j}$

In Figure 28, the real and calculated value of decrease in bending stiffness for experimental obtained displacement influence lines are shown.

\section{Discussion}

As it can be seen from conducted numerical simulations in Chapter 3, all simulated damages are located, regardless of member of obtained data. The proposed procedure successfully locate edge damage near the support where bending moments are close to zero, what is lack of many methods based on comparison of curvatures (Štimac 2006; Štimac, Kožar 2005). Also the procedure is able to locate double damages.

The comparison of calculated and simulated values of decrease in bending stiffness are shown in Table 2 as deviation $\Delta=\left(\left(\delta_{j}^{c a l} / \delta_{j}^{\text {sim }}\right)-1\right) \cdot 100 \%$, where $\delta_{j}^{c a l}$ and $\delta_{j}^{\text {sim }}$ are calculated and simulated values of decrease in bending stiffness, respectively.

Table 2. Deviation $\Delta$ of calculated and simulated values of decrease in bending stiffness [\%]

\begin{tabular}{c|c|c|c}
\hline $\begin{array}{c}\text { Damage } \\
\text { scenario }\end{array}$ & $n=40$ & $n=20$ & $n=10$ \\
\hline 1 & 6 & 10 & 20 \\
2 & 11 & 17 & 34 \\
3 & 5 & 10 & 12 \\
4 & 11 & 17 & 24 \\
5 & 18 & 27 & 39 \\
6 & -28 & -80 & -90 \\
7 & 18 and 18 & 27 and 27 & 39 and 40 \\
\hline
\end{tabular}

The values of calculated bending stiffness reduction are overestimated in all positions of damage(s) except the edge damage position, in segment $j=1$, where the calculated values are underestimated in regard to simulated ones. The main reason of underestimation of damage in edge segment $(j=1)$ is lack of curvature in position $x_{0}$. It is especially expressed in the simulation with $d=0.5$ and $d=1$, where the calculated value of curvature is positioned on the right edge segment, and the damage is located along the left edge segment at the length of $0.25 \mathrm{~m}$. It can be concluded that proposed method is successful in location of damage in edge segments, but evaluation of damage severity depend of sparseness of measurement and position of damage between two obtained data and may result in great underestimation of damage severity. 
In middle segments the accuracy of estimated damage is associated with number of obtained data and severity of simulated damage: the least deviation $\Delta$ of $5 \%$ and $6 \%$ of calculated decrease in bending stiffness in regard to simulated ones is in case of the densest data network and the smallest simulated damage $(n=40$ and $\left.\delta_{j}^{\text {sim }}=10 \%\right)$. The greatest deviation $\Delta$ of $39 \%$ and $40 \%$, are calculated in cases of the rarest data network and the greatest simulated damage $\left(n=10\right.$ and $\left.\delta_{j} \operatorname{sim}=30 \%\right)$.

Generally, the denser network of obtained data gives more accurate values of bending stiffness reduction. For the distance of obtained data $d=0.25 \mathrm{~m}$, which is identical to damage length, the deviations $\Delta$ are from $6 \%$ to $18 \%$. When the distance of obtained data $(d=0.5 \mathrm{~m})$ is twice the damage length the deviations $\Delta$ are between $10 \%$ and $27 \%$. In case of $d=1 \mathrm{~m}$ (the distance of obtained data is four times the damage length) the deviations $\Delta$ are between $20 \%$ and $40 \%$.

In Chapter 4, the result of experimental validation of proposed method shows that the damage is located in $8^{\text {th }}$ segment, i.e. between 1.6 to 1.8 meters from the left support, what is in accordance with real position of damage. The deviation $\Delta$ of calculated and real value of decrease in bending stiffness in damaged segment is $18 \%$ which is expected in the light of the results of numerical simulations.

In existing papers dealing with damage localization and estimation of damage severity using only static displacements the deviation of simulated and calculated values of damage are up to $18 \%$ (Yang, Sun 2011), 20\% (Maity, Saha 2004), 30\% (Terlaje, Truman 2007), 40\% (Bakhtiari-Nejad et al. 2005), 60\% (Chen et al. 2005). The method proposed by RaghuPrasad et al. (2013) gives the smallest deviation of simulated and calculated damages of $8 \%$, but the method is limited to detection and severity estimation of single damage. In all these damage severity estimation methods the length of damage was equal to the length taken into damage estimation analysis (whole segment length); no one deals with detection and severity estimation of damages shorter than the segment. Also, none of them deal with estimation of damage near the pinned support.

Comparison of accuracy of damage severity estimation found in existing literature with those achieved in this paper shows that proposed damage severity estimation procedure based on simple arithmetic operation is competitive to much more complex methods mentioned previously.

\section{Conclusions}

In the paper, the novel approach in damage severity estimation in beams based on curvature of displacement influence lines and grey coefficient using sparse static measurements is proposed. The main advantage of the proposed procedure is simplicity of mathematical operations used in determination of damage location and severity. According to conducted numerical simulations on a simply supported beam with different position and severity of damage and different data sparseness it can be concluded that:

- all simulated damages are located regardless of data sparseness;

- the severity of damage in middle segments is overestimated from $5 \%$ to $40 \%$ depending on simulated damage severity and sparseness of data;

- the severity of damage in edge segments (near pinned support) can be greatly underestimated.

Generally, the proposed procedure is successful in damage location. The severity of damage in middle segments can be identified with a degree of accuracy comparable with more complex estimation procedure. The experimental validation on a beam with single damage confirms the results of numerical simulations.

The behaviour of existing structures is usually influenced by the adjacently connected non-structural elements which may contribute to the stiffness of whole structure. In such a case the proposed method, as well as any other global method, can estimate the stiffness changes in general, no meter the damage is occurred in the main load bearing elements and/or in the non-structural elements.

Once damage is detected, located and roughly estimated using proposed global method some local technique can be employed to examine the damage location in detail.

\section{Acknowledgements}

This work has been partially supported by University of Rijeka through grant No. 13.05.1.1.01 and the authors are gratefully for this support.

\section{References}

Abdo, M. A.-B. 2012. Parametric study of using only static response in structural damage detection, Engineering Structures 34: 124-131.

http://dx.doi.org/10.1016/j.engstruct.2011.09.027

Bakhtiari-Nejad, F.; Rahaib, A.; Esfandiarib, A. 2005. A structural damage detection method using static noisy data, Structural Engineering 27(12): 1784-1793.

http://dx.doi.org/10.1016/j.engstruct.2005.04.019

Buda, G.; Caddemi, S. 2007. Identification of concrete damages in Euler-Bernoulli beams under static loads, Journal of Engineering Mechanics 133(8): 942-956.

http://dx.doi.org/10.1061/(ASCE)0733-9399(2007)133:8(942)

Capozucca, R. 2008. Detection of damage due to corrosion in prestressed RC beams by static and dynamic tests, Construction and Building Materials 22(5): 738-746. http://dx.doi.org/10.1016/j.conbuildmat.2007.01.025

Chen, H. P.; Bicanic, N. 2000. Assessment of damage in continuum structures based on incomplete modal information, Computers \& Structures 74(5): 559-570. http://dx.doi.org/10.1016/S0045-7949(99)00062-0

Chen, X.-Z.; Zhu, H.-P.; Chen, C.-Y. 2005. Structural damage identification using test static data based on grey system theory, Journal of Zhejiang University SCIENCE (JZUS) 6A(8): 790-796. http://dx.doi.org/10.1631/jzus.2005.A0790

Choi, I.; Lee, J. S.; Choi, E.; Cho, H. N. 2004. Development of elastic damage load theorem for damage detection in 
statically determinate beam, Computers \& Structures 82(29-30): 2483-2492.

http://dx.doi.org/10.1016/j.compstruc.2004.07.003

Cornwell, P.; Doebling, S. W.; Farrar, C. R. 1999. Application of the strain energy damage detection method to platelike structures, Journal of Sound and Vibration 224(2): 359-374. http://dx.doi.org/10.1006/jsvi.1999.2163

Fayyadha, M. M.; Razaka, H. A. 2013. Damage identification and assessment in RC structures using vibration data: a review, Journal of Civil Engineering and Management 19(3): 375-386. http://dx.doi.org/10.3846/13923730.2012.744773

Garstecki, A.; Knitter-Piatkowska, A.; Pozorski, Z.; Ziopaja, K. 2004. Damage detection using parameter dependent dynamic experiments and wavelet transformation, Journal of Civil Engineering and Management 10(3): 191-197. http://dx.doi.org/10.1080/13923730.2004.9636306

Kim, B. H.; Park, T.; Voyiadjis, G. Z. 2006. Damage estimation on beam-like structures using the multi-resolution analysis, International Journal of Solids and Structures 43(14-15): 4238-4257. http://dx.doi.org/10.1016/j.ijsolstr.2005.07.022

Lee, E.-T.; Eun, H.-C. 2008. Damage detection of damaged beam by constrained displacement curvature, Journal of Mechanical Science and Technology 22(6): 1111-1120. http://dx.doi.org/10.1007/s12206-008-0310-3

Li, Y. Y.; Chenga, L.; Yama, L. H.; Wonga, W. O. 2002. Identification of damage locations for plate-like structures using damage sensitive indices: strain modal approach, Computers \& Structures 80(25): 1881-1894. http://dx.doi.org/10.1016/S0045-7949(02)00209-2

Maity, D.; Saha, A. 2004. Damage assessment in structure from changes in static parameter using neural networks, Sadhana 29(3): 315-327. http://dx.doi.org/10.1007/BF02703781

Ndambi, J. M.; Peeters, B.; Maeck, J.; De Visscher, J.; Wahab, M. A.; Vantomme, J.; De Roeck, G.; De Wilde, W. P. 2000. Comparison of techniques for modal analysis of concrete structures, Engineering Structures 22(9): 11591166. http://dx.doi.org/10.1016/S0141-0296(99)00054-1

Ndambi, J. M.; Vantomme, J.; Harri, K. 2002. Damage assessment on reinforced concrete beam using eigenfrequencies and mode shape derivatives, Engineering Structures 24(4): 501-515. http://dx.doi.org/10.1016/S0141-0296(01)00117-1

Nicholson, D. W.; Alnefaie, K. A. 2000. Modal moment index for damage detection in beam structures, Acta Mechanica 144(3-4): 155-167. http://dx.doi.org/10.1007/BF01170172

RaghuPrasad, B. K.; Lakshmanan, N.; Gopalakrishnan, N.; Sathishkumar, K.; Sreekala, R. 2013. Damage identification of beam-like structures with contiguous and distributed damage, Structural Control Health Monitoring 20(4): 496-519. http://dx.doi.org/10.1002/stc.511

Reddy, C. S. 1996. Basic structural analysis. New Delhi, India: Tata McGraw-Hill Publication Company Limited. 777 p.

Stöhr, S.; Link, M.; Rohrmann, R. G.; Rücker, W. 2006. Damage detection based on static measurements on bridge structures, in Proc. of the $24^{\text {th }}$ Conference and Exposition on Structural Dynamics, 30 January - 2 February 2006, St Louis, Missouri, USA, 5: 2530-2541.

Sanayei, M.; Imbaro, G.; McClain, J.; Brown, L. 1997. Structural model updating using experimental static measurements, Journal of Structural Engineering 123(6): 792-798.

http://dx.doi.org/10.1061/(ASCE)0733-9445(1997)123:6(792)

Seyedpoor, S. M.; Yazdanpanah, O. 2013. An efficient indicator for structural damage localization using the change of strain energy based on static noisy data, Applied Mathematical Modelling 38(9-10): 2661-2672. http://dx.doi.org/10.1016/j.apm.2013.10.072

Štimac Grandić, I.; Grandić, D. 2010. Evaluation of structural damage in beam structures using the strain energy method, in Proc. of the $10^{\text {th }}$ International Conference on Computational Structures Technology (CST 2010), 14-17 September 2010, Valencia, Spain, 1-11.

http://dx.doi.org/10.4203/ccp.93.62

Štimac Grandić, I.; Grandić, D; Bjelanović, A. 2011. Comparison of techniques for damage identification based on influence line approach, Machines, Technologies, Materials 7: 9-13.

Štimac Grandić, I.; Mihanović, A.; Kožar, I. 2009. Otkrivanje oštećnja ploča usporedbom zakrivljenosti utjecajnih ploha progiba, Građevinar 61(3): 231-241 (in Croatian).

Štimac, I.; Kožar, I.; Mihanović, A. 2007. Otkrivanje oštećenja greda s pomoću utjecajnih linija progiba, Građevinar 59(12): 1053-1066 (in Croatian).

Štimac, I. 2006. Uporaba utjecajnih linija progiba u otkrivanju oštećenja konstrukcija: Disertacija. Split. 137 p. (in Croatian).

Štimac, I.; Kožar, I. 2005. Damage detection from displacement-in-time function, in Proc. of the $4^{\text {th }}$ Youth Symposium on Experimental Solid Mechanics, 4-7 May 2005, Castrocaro Terme, Italy, 3-4.

Terlaje, A. S.; Truman, K. Z. 2007. Parameter identification and damage detection using structural optimization and static response data, Advances is Structural Engineering 10(6): 607-621. http://dx.doi.org/10.1260/136943307783571409

Viola, E.; Bocchini, P. 2013. Non-destructive parametric system identification and damage detection in truss structures by static tests, Structure and Infrastructure Engineering: Maintenance, Management, Life-Cycle Design and Performance 9(5): 384-402. http://dx.doi.org/10.1080/15732479.2011.560164

Wang, S. 2013. Iterative modal strain energy method for damage severity estimation using frequency measurements, Structural Control and Health Monitoring 20(2): 230240. http://dx.doi.org/10.1002/stc.495

Wang, C. Y.; Huang, C. K.; Chen, C. S. 2011. Damage assessment of beam by a quasi-static moving vehicular load, Advances in Adaptive Data Analysis 3(4): 417-445. http://dx.doi.org/10.1142/S1793536911000908

Yang, Q. W.; Sun, B. X. 2011. Structural damage localization and quantification using static test data, Structural Health Monitoring 10(4): 381-389.

http://dx.doi.org/10.1177/1475921710379517

Ivana ŠTIMAC GRANDIĆ. Associate professor in the Department for Structures and Technical Mechanics at Faculty of Civil Engineering, University of Rijeka. She received her MS from faculty of Civil Engineering, University of Zagreb in 2003 and PhD from Faculty of Civil Engineering and Architecture, University of Split in 2006. She is a member of Croatian Technical Subcommittee PO1 (Action on structures). Main research interests: damage detection assessment, concrete bridge structures, pedestrian induced vibration in structures.

Davor GRANDIĆ. Associate professor in the Department for Structures and Technical Mechanics at Faculty of Civil Engineering, University of Rijeka. He received his MS in 2001 and PhD in 2008 from Faculty of Civil Engineering, University of Zagreb. He is a member of Croatian Technical Committee TO 485, a chairman of Croatian Technical Subcommittee PO8 (Design of structures for earthquake resistance) and a member of Croatian Technical Subcommittees PO2 (Design of concrete structures) and PO6 (Design of masonry structures). He has worked 10 years in Institute of Civil Engineering of Croatia. He is also a certified professional constructor. Main research interests: theoretical basis of design of concrete and masonry structures, effects of reinforcement corrosion in concrete on structural performances, earthquake engineering and structural repair and rehabilitation of existing structures. 